\title{
Adoptive Natural Killer Cell Immunotherapy for Canine Osteosarcoma
}

\author{
William C. Kisseberth ${ }^{1 *}$ and Dean A. Lee ${ }^{2}$ \\ ${ }^{1}$ Department of Veterinary Clinical Sciences, The Ohio State University, Columbus, OH, United States, ${ }^{2}$ Department of \\ Pediatrics, Nationwide Children's Hospital and The Ohio State University Comprehensive Cancer Center, Columbus, OH, \\ United States
}

\section{OPEN ACCESS}

Edited by:

Leonardo Della Salda, University of Teramo, Italy

Reviewed by:

Sang-ki Kim,

Kongju National University,

South Korea

Brina Lopez,

Midwestern University, United States

*Correspondence:

William C. Kisseberth

kisseberth.2@osu.edu

Specialty section:

This article was submitted to Comparative and Clinical Medicine, a section of the journal

Frontiers in Veterinary Science

Received: 25 February 2021 Accepted: 05 May 2021

Published: 07 June 2021

Citation:

Kisseberth WC and Lee DA (2021) Adoptive Natural Killer Cell Immunotherapy for Canine Osteosarcoma

Front. Vet. Sci. 8:672361 doi: 10.3389/fvets.2021.672361
Osteosarcoma is the most common primary bone tumor in both humans and dogs. It is a highly metastatic cancer and therapy has not improved significantly since the inclusion of adjuvant chemotherapy into disease treatment strategies. Osteosarcoma is an immunogenic tumor, and thus development of immunotherapies for its treatment, especially treatment of microscopic pulmonary metastases might improve outcomes. NK cells are lymphocytes of the innate immune system and can recognize a variety of stressed cells, including cancer cells, in the absence of major histocompatibility complex (MHC)-restricted receptor ligand interactions. NK cells have a role in controlling tumor progression and metastasis and are important mediators of different therapeutic interventions. The core hypothesis of adoptive natural killer (NK) cell therapy is there exists a natural defect in innate immunity (a combination of cancer-induced reduction in NK cell numbers and immunosuppressive mechanisms resulting in suppressed function) that can be restored by adoptive transfer of NK cells. Here, we review the rationale for adoptive NK cell immunotherapy, NK cell biology, TGF $\beta$ and the immunosuppressive microenvironment in osteosarcoma, manufacturing of ex vivo expanded NK cells for the dog and provide perspective on the present and future clinical applications of adoptive NK cell immunotherapy in spontaneous osteosarcoma and other cancers in the dog.

Keywords: canine, immunotherapy, osteosarcoma, NK cell, TGF $\beta$

\section{INTRODUCTION}

Osteosarcoma is the most common primary bone tumor in both humans and dogs, with the disease incidence being as much as 30-50 times higher in the latter (1). The similarities of the disease in humans and dogs are well-described and include commonalities in underlying molecular biology, including gene expression and genetic mutations, histopathology, clinical presentation, disease progression, and response to therapy (2). Spontaneous osteosarcoma in the dog has been used extensively as a preclinical large animal model to evaluate new therapies for osteosarcoma in humans, including limb-sparing procedures (3-5), chemotherapy delivery $(6,7)$, targeted therapeutics (8), and immunotherapeutics, including therapeutic vaccines and others (911). New immunotherapeutic approaches to cancer treatment have emerged and are now making a significant clinical impact for large numbers of cancer patients $(12,13)$. The development of new immunotherapeutics can be greatly facilitated by the use of well-characterized and validated animal models and spontaneously occurring osteosarcoma in pet dogs is exceptionally well-suited 
for this purpose. In addition to the similarities described above, other features of the disease in dogs are particularly relevant and important for evaluating immunotherapeutic interventions. Notably, cancers in dogs occur in a relatively outbred population that generally shares similar environmental exposures with humans and the spontaneously occurring tumors are heterogeneous, existing in a complex microenvironment and in a host with an intact immune system; all critical features that are poorly addressed in most rodent models (14).

\section{RATIONALE FOR ADOPTIVE NK CELL IMMUNOTHERAPY}

The core hypothesis of adoptive natural killer (NK) cell immunotherapy is that there exists a natural defect in innate immunity (a combination of cancer-induced reduction in NK cell numbers and immunosuppressive mechanisms resulting in suppressed function) that can be restored by adoptive transfer of NK cells (15). The immunosuppressive tumor microenvironment suppresses NK cell function (16), and although many drugs and radiation can sensitize tumors for recognition by NK cells, chemotherapy, anesthesia, and radiation therapies can also adversely affect NK cell numbers and function (17-21). While much effort has gone into T-cell based approaches for immunotherapy, including chimeric antigen receptor (CAR) Tcells and immune checkpoint inhibition, these approaches can have significant problems that may impede their application such as graft-vs. host disease (GVHD), cytokine release syndrome (CRS), immune effector cell-associated neurotoxicity syndrome (ICANS), or severe on-target off-tissue toxicities $(22,23)$. Adoptive NK cell therapy is not associated with GVHD (24), thus making it potentially safer than T-cell based therapies and because allogeneic transfer is tolerated, NK cell products can be manufactured and stored for later use in patients as needed, rather than manufacturing "on-demand" for patient-specific use.

\section{NK CELL BIOLOGY}

NK cells are lymphocytes of the innate immune system. NK cells can recognize a variety of stressed cells in the absence of major histocompatibility complex (MHC)-restricted receptor ligand interactions. NK cells are non-T, non-B lymphocytes, and are known for their cytotoxicity and cytokine effector functions. Importantly, they can kill target cells without prior antigen sensitization. Also, NK cells can cross-talk with dendritic cells in different ways, thus participating in the shaping of the subsequent immune response. NK cells have a role in controlling tumor progression and metastasis and are important mediators of different therapeutic interventions, including cytokines, antibodies, immunomodulatory drugs, and stem cell transplantation.

\section{NK Cell Receptors and Function}

The number of NK cells as a percentage of peripheral lymphocytes varies widely in humans (1-32.6\%, median $7.6 \%$ ) and in dogs (2.5-15\%) (25-29). In humans, NK cells are identified by the lack of CD3 and the presence of CD56 and/or CD16, and make up $85 \%$ of the large granular lymphocyte (LGL) population (30). The phenotypic characteristics of NK cells in the dog are not as clearly defined; however, distinct phenotypic NK cell subsets have been described (31). NK cells express many different cell surface receptors that can be grouped as activating, inhibitory, adhesion, cytokine, or chemotactic receptors. Although many of the cell surface molecules involved in the regulation of $\mathrm{NK}$ cell function are found in both humans and mice, only a small subset has been validated in the dog. Canine NK cells do express at the mRNA level several genes classically associated with NK cells, such as NKp30, NKp44, NKp46, NKG2D, CD16, DNAM-1, perforin, and granzyme B (25).

The regulation of $\mathrm{NK}$ cell function relies on a complex interplay of activating and inhibitory signals. Unlike T-cells, whose activation is highly restricted to an antigenic peptide presented in the groove of MHC proteins, NK cell activation is not antigen specific. NK cell activation and tolerance are accomplished through a large variety of activating receptors for recognition of danger, balanced with an equally large number of inhibitory receptors that identify self. The balance between these signals determines whether NK cells will activate their effector function (e.g., FasL/TRAIL-mediated killing, perforin/granzyme release, or cytokine production). In humans, there are several families of activating receptors, including CD126 (FcR $\gamma \mathrm{III}$ ), natural cytotoxicity receptors (NCRs), NK Group 2 (NKG2) lectin-like receptors, DNAM-1, and 2B4; however, most of these have not been well-characterized in the dog (32). Activating receptors generally recognize proteins that are upregulated by cell stress or are of non-self-origin, whereas inhibitory receptors primarily bind $\mathrm{MHC}$ for self-recognition (33). Inhibitory receptors provide control for $\mathrm{NK}$ cell activity against healthy tissue. The primary inhibitory receptors in human NK cells are killer-cell immunoglobulin-like receptors (KIRs) and NKG2A, both of which bind to HLA class I molecules, preventing NK cell-mediated lysis of cells with normal HLA expression (33). MHC class-I deficient targets have heightened sensitivity to NK cell killing. This biology is reflected and summarized by the "missing self" hypothesis, which states that the presence of MHC class I, ubiquitously expressed by healthy cells, provides NK cells with a "self" signal that is recognized by NK cell inhibitory receptors and thus prevents NK cell selfreactivity (34).

\section{Canine NK Cells}

While human NK cells are distinguished by the absence of surface expression of $\mathrm{CD} 3$ and the presence of variable levels of expression of CD56 and CD16, depending on differentiation state (35), the phenotypic characterization of canine NK cells is still evolving. Morphologically, canine NK cells are medium- to large-sized lymphocytes containing electrondense intracytoplasmic granules that contain granzyme B and perforin and lack expression of CD4 and CD20, T-cell and B-cell markers, respectively (36). However, CD8 may be expressed by a subset of these cells $(37,38)$. Canine NK cell populations have also been defined based on density of 
CD5 surface marker expression, with $\mathrm{CD} 5^{\text {dim }}$ representing a NK cell population (28), especially in the setting of IL-2 stimulation. Further, under ex vivo expansion conditions with cytokine stimulation, the majority of cytotoxic large granular lymphocytes expressed a $\mathrm{CD} 5^{\mathrm{dim}} \mathrm{CD} 3^{+} \mathrm{CD} 8^{+} \mathrm{TCR} \alpha \beta^{-} \mathrm{TCR} \gamma \delta$ ${ }^{-} \mathrm{CD} 4{ }^{-} \mathrm{CD} 21^{-} \mathrm{CD} 11 \mathrm{c}^{+/-} \mathrm{CD} 11 \mathrm{~d}^{+/-} \mathrm{CD} 44^{+}$phenotype that highly upregulated NKp46, and expressed traditional T-cell lineage markers, but lacked T-cell receptors (39). NCR1/NKp46, a NK-specific activating molecule, is considered a "pan-species" NK cell marker (40). One study concluded that canine NK cells are comprised of both $\mathrm{CD}^{-}$GranzymeB $^{+} \mathrm{NCR}^{+}$and $\mathrm{CD}^{-}{ }^{-} \mathrm{GranzymeB}^{+} \mathrm{NCR}^{-}$populations cells, with the presence of NCR1/NKp46 positive cells representing an activated state $(27,31)$. Similarly, a canine-specific antibody to NKp46 identifies $\mathrm{CD}^{-}{ }^{-} \mathrm{NKp} 46^{+}$and $\mathrm{CD}^{-} \mathrm{NKp} 46^{-} \mathrm{NK}$ subsets that vary in cytotoxicity, with $\mathrm{CD}^{-} \mathrm{NKp} 46^{-}$population being less cytotoxic, but could be induced to express NKp46 (25). Another putative marker for canine NK cells is the C-type lectin-like CD94 (KLRD-1). Experiments with a canine-specific anti-CD94 identifies a candidate NK cell population representing $\sim 7.7 \%$ of PBMCs and subsets within the $\mathrm{CD} 5^{\mathrm{dim}}$ population (26). It should be noted that the KIR family of surface receptors described above for humans has not been identified in dogs. One gene of a similar paralogous family found in mice, the Ly49 family, has been identified in the canine genome $(39,41)$.

\section{MECHANISMS OF NK CELL KILLING}

NK cells exert direct and indirect antitumor activity and kill target tumor cells via release of granules containing perforin and granzyme, secretion of cytokines such as IFN $\gamma$ and other effector molecules, ligation and activation of death receptors, and antibody-dependent cellular toxicity (ADCC) mediated through CD16 when combined with anti-tumor antibodies. Further, the release of pro-inflammatory cytokines enhances the recruitment and maturation of adaptive immune responses (42, 43). The mechanism by which NK cells induce apoptosis in osteosarcoma cells may depend on both the activation state of the NK cells and the death receptor and apoptotic pathways present and functional in the target cell (33). For example, in vitro, direct NK cell lysis of osteosarcoma cells is mediated via direct release of granzyme B (44); however, granule-independent mechanisms may be more relevant in vivo, as losing Fas and TRAIL may be simpler mechanisms of escape than redundant downstream death pathways (45). Degranulation of NK cells is mediated by the balance of activating and inhibitory receptors, which in turn is influenced by the expression of ligands on the tumor cell. This suggests that NK cells isolated, expanded, and activated using different techniques may differ as to which activating receptors are highly expressed and important for recognizing a particular tumor (33). For example, in one study IL-15 stimulated NK cells targeted osteosarcoma predominantly through DNAM1, whereas in another study IL-2 stimulated NK cells targeted osteosarcoma predominantly through NKG2D $(44,46)$.

\section{OSTEOSARCOMA, THE IMMUNOSUPPRESSIVE MICROENVIRONMENT, AND TGF $\beta$}

Tumors, especially solid tumors, have evolved mechanisms to actively suppress the immune system. These include induction of inhibitory receptors on NK and T-cells, recruitment of Tregs, myeloid derived suppressor cells and tumor associated macrophage, and production of immunosuppressive cytokines and other factors, including TGF $\beta$ (47). Overexpression of TGF $\beta$ is a hallmark of many cancers, including osteosarcoma. It inhibits NK cell activity through several mechanismssuppressing NKG2D and CD16 expression, decreasing perforin, and inhibiting cytokine release (48-51). TGF $\beta$ is highly expressed in cancer cell lines and notably, is more highly expressed in osteosarcoma than most other solid tumor cell lines, suggesting that TGF $\beta$ is an important contributor to the immunosuppressive tumor microenvironment for osteosarcoma in particular (52). TGF $\beta$ signaling is a crucial factor in crosstalk between osteosarcoma cells and stroma cells. Secretion of TGF $\beta$ by tumor cells or stroma cells can act in a paracrine manner to regulate the tumor microenvironment, promoting angiogenesis, bone remodeling and cell migration, and by inhibiting immunosurveillance. TGF $\beta$ secretion and TGF $\beta$ receptor expression has been demonstrated in canine osteosarcoma cells (53). Our group has developed a NK cell expansion technique that confers relative TGF $\beta$-resistance to NK cells in an attempt to improve their function in the hostile immunosuppressive tumor microenvironment (54). TGF $\beta$ resistance, or imprinting, is achieved by chronic exposure of NK cells to IL-2 and TGF $\beta$ during the expansion process. TGF $\beta$-imprinted NK cells secrete more IFN $\gamma$ and TNF $\alpha$ than non-imprinted NK cells in the absence, or presence, of TGF $\beta$. Furthermore, TGF $\beta$-imprinted NK cells have increased cellular toxicity compared to non-imprinted cells and are more resistant to TGF $\beta$-mediated decreases in cellular cytotoxicity (54). Ex vivo expanded canine NK cells cultured under similar conditions are likewise conferred relative TGF $\beta$-resistance (Lee, unpublished).

\section{MANUFACTURING OF EX VIVO-EXPANDED CANINE NK CELLS FOR ADOPTIVE IMMUNOTHERAPY}

NK cells for clinical use can be obtained through apheresis with T-cell depletion, or by ex vivo expansion. In humans, NK cells have been successfully expanded from peripheral blood, cord blood, and pluripotent or embryonic stem cells (55). Various methods for expanding purified NK cell populations have been developed in people, using exposure to different cytokines and co-culture with feeder cell lines $(15,55)$. Several of these methods have been extrapolated to and modified for canine studies $(25,56)$. In general, superior expansion is achieved when recombinant canine cytokines are used vs. recombinant human cytokines. In humans, the incorporation of IL-21 cytokine exposure by co-culture with the K562 feeder 


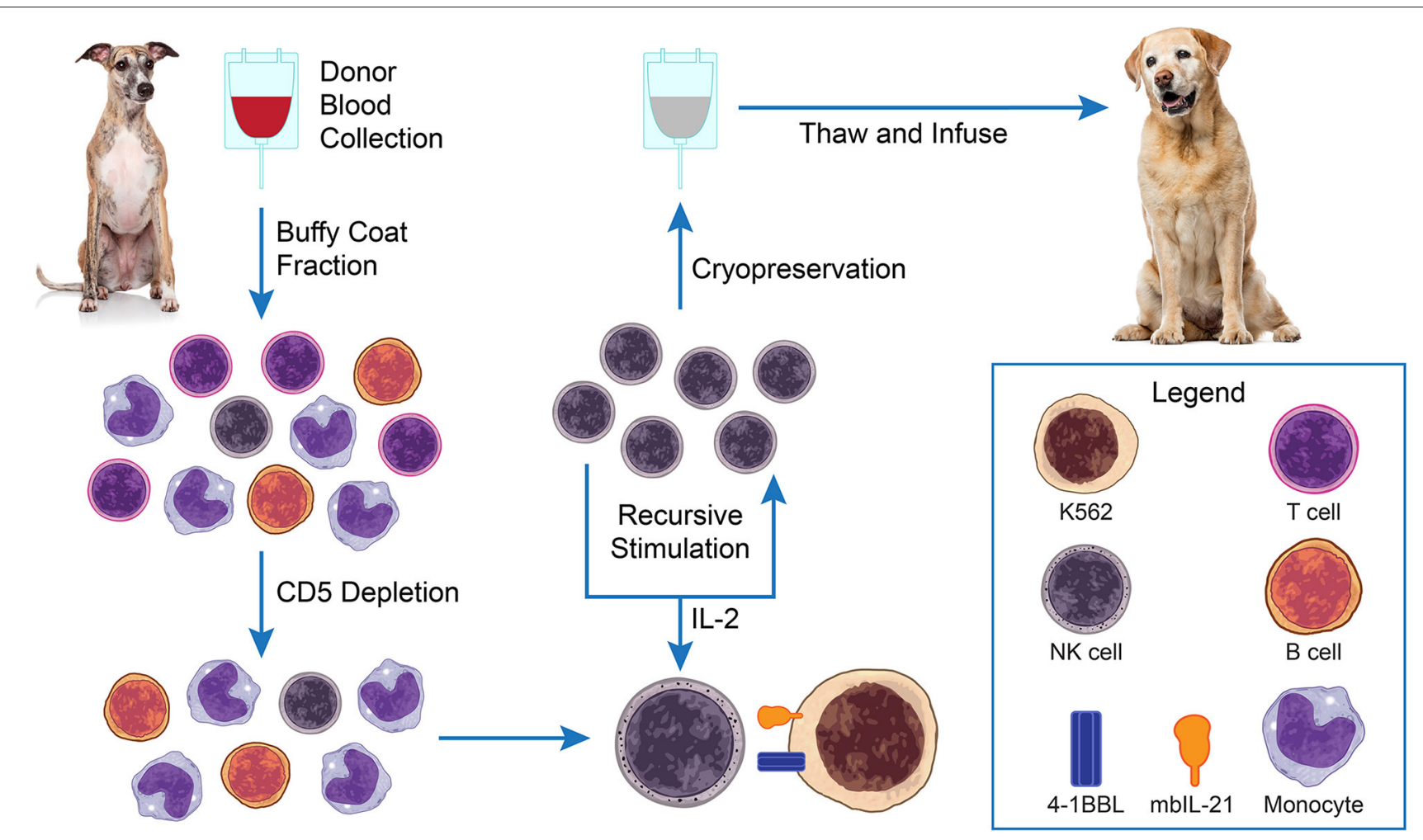

FIGURE 1 | Adoptive natural killer (NK) cell therapy. PBMCs are isolated from blood buffy coats of healthy blood donor dogs by Ficoll separation. The separated cells undergo CD5 cell depletion and are then co-cultured and recursively stimulated in the presence of IL-2 ( \pm TGF $\beta$ ) 3x over a 3-week period with irradiated K562 feeder cells expressing membrane bound IL-21. Expanded NK cells can be used immediately, or cryopreserved for later use.

cell line, significantly enhanced NK cell expansion in IL-15/IL-2 expanded NK cells (55).

These techniques have been modified by our group to manufacture ex vivo expanded canine NK cells with similarly robust results (25). Clinical grade expanded NK cells are produced using good manufacturing practices (GMP) principles including closed-system processes and standardized release testing and certification criteria. For our studies, the primary donor NK cells used for expansion are obtained from the buffy coats of routine whole blood donations from healthy volunteer canine blood bank donors at our veterinary medical center. Peripheral blood mononuclear cells (PBMCs) are isolated by Ficoll separation from the buffy coats. The separated cells undergo CD5 cell depletion and are then co-cultured and recursively stimulated in the presence of IL- 2 three times over a 3 week period with irradiated human K562 feeder cells expressing the co-stimulatory ligand 4-1BBL and membrane bound IL-21 (Figure 1). The final ex vivo expanded NK cell product release criteria include: $\geq 70 \%$ viability, CD3 + cells $<5 \%, \mathrm{NKp} 46+$ cells as reported, endotoxin $<5 \mathrm{EU} / \mathrm{kg}$, and mycoplasma negative. Expanded NK cells can be used immediately, or cryopreserved for later use.

The influence and importance of the donor on the final NK cell product is largely unexplored, although there does appear to be individual donor variability in the robustness of expansion and in vitro cytotoxicity of the final expanded NK cell product.
The influence of donor breed is also unknown. A preliminary survey of NK cell numbers (NKp46+, CD3-) and expression of DNAM-1 and TIM-3 receptors in the four most common donor breeds (greyhound, pit bull, golden retriever, and Labrador retriever) in our blood bank showed minor breed differences with no one breed being a clearly superior donor source (Peck, unpublished). Ultimately, for our initial clinical trials, we chose to use greyhound donors exclusively, as they are the most common breed in our blood donor population and by doing so, any unknown breed associated variability in the final product could be excluded.

\section{CLINICAL APPLICATION OF ADOPTIVE NK CELL IMMUNOTHERAPY IN CANINE OSTEOSARCOMA}

As described above, spontaneous osteosarcoma in pet dogs provides an ideal large animal translational model for studying new immuno-oncology approaches for treating this cancer, including adoptive NK cell therapy. The more recent development of canine-specific antibodies for identifying canine NK cells and subsets, adaptation and development of ex vivo NK cell expansion techniques, and overall gradually increasing availability of canine-specific reagents and analysis techniques, now makes clinical trials of adoptive NK cell therapy 
for osteosarcoma and other cancers in dogs more feasible and informative. However, these studies and trials are only just now beginning.

The first reported clinical trial of adoptive NK cell immunotherapy in dogs with appendicular osteosarcoma evaluated autologous ex vivo expanded NK cells administered intra-tumorally following completion of a hypo-fractionated palliative radiation protocol (56). In this study, NK cells were isolated and expanded from the canine patient using an expansion technique similar to that described above (56). Two injections of $7.5 \times 10^{6} \mathrm{NK}$ cells/kg were co-injected with 250,000 $\mathrm{IU} / \mathrm{kg}$ of rhIL-2. Ten dogs were treated in this study. Overall, there was limited systemic toxicity with this protocol. One dog had a grade 3 reaction of fever, chills, excessive salivation, and dehydration consistent with IL-2 toxicity. Three dogs had local infection/tissue breakdown at the NK cell injection site. Persistence of labeled viable NK cells could be demonstrated in tumor biopsies performed 1 week after intra-tumoral injection. Interestingly, analysis of PBMCs pre- and post-treatment demonstrated a significant increase in circulating granzyme $\mathrm{B}+$ CD45+ cells (56).

Our group recently opened a phase I clinical trial of intravenously administered allogeneic TGF $\beta$-resistant (imprinted) NK cells combined with adjuvant carboplatin chemotherapy in dogs with appendicular osteosarcoma receiving limb amputation (54). In this trial, dogs receive a single dose of NK cells $24 \mathrm{~h}$ prior to amputation to evaluate NK cell trafficking to the primary tumor. Three additional doses are administered during the subsequent $48 \mathrm{~h}$ post-amputation period. Dogs then receive standard adjuvant carboplatin chemotherapy every 3 weeks, with additional NK cell doses administered on the weeks they are not receiving chemotherapy. In total, dogs receive a total of twelve doses of adoptive NK cells-significantly more doses than in most human NK cell immunotherapy trials, to date. The use of allogeneic NK cells greatly increases the yield and potential cell doses, reduces the cost of therapy, and simplifies the logistics for delivery. Although this approach requires cryopreservation of the product which may impact NK cell viability and function, we have successfully used cryopreserved NK cells for several human studies $(57,58)$.

One of the major strengths of clinical trials in dogs with spontaneously occurring cancers is the ability to do intensive longitudinal patient biospecimen sampling and clinical assessments, often more intensively than is possible in a comparable clinical trial in human patients. This is wellillustrated in the afore described first-in-dog clinical trial, where pre- and post-treatment serum cytokine concentrations were assessed by ELISA, tumor gene expression profiles by qRT-PCR, circulating immune cell phenotypes by flow cytometry, and intra-tumoral immune cell phenotypes by immunohistochemistry and qRT-PCR (59). Gradually increasing availability of new canine-specific reagents and application of new technologies to the dog, will further increase the number and power of the correlative studies that can be done and their translational relevance.

Understanding of the pharmacokinetics and trafficking of adoptively transferred NK cells and consequent effects on systemic and tumor immune cell phenotypes and responses to therapy are important biological correlates for assessing adoptive NK cell strategies and in principle can be addressed in this model using a variety of approaches. Assessment of circulating NK cell numbers and phenotypes in blood can be assessed by flow cytometry; however, distinguishing donor from patient cells is problematic. Optimization of variable number tandem repeat PCR assays as is used to assess tissue chimerism in human transplant patients (60) and experimental canine bone marrow transplant models (61-63), may be useful for assessing the relative circulating donor NK cell component. Sex chromosome (XX/XY) FISH chimerism testing may be another method that could be applied when there is a sex-mismatched donor (64). Novel cell labeling agents have been developed and tested in rodent and nonhuman primate models and could be useful for evaluating NK cell kinetics and trafficking in the canine osteosarcoma model. Ex vivo-expanded human NK cells labeled with the non-radioactive isotope fluorine $19\left({ }^{19} \mathrm{~F}\right)$ can be detected in rodent tissues by $\mathrm{NMR}$ and imaged with ${ }^{19} \mathrm{~F}-\mathrm{MRI}$ (65, 66). Similarly, expanded NK cells from rhesus macques were labeled with ${ }^{89}$ zirconium-oxine $\left({ }^{89} \mathrm{Zr}\right.$-oxine) cell labeling and quantitated and imaged with positron emission tomography (PET)/CT (67).

\section{FUTURE APPLICATIONS}

While these early studies of adoptive NK cell therapy in dogs are demonstrating the feasibility, tolerability, and safety of the approach, the model is well-suited for investigating many ongoing and new important questions in the field. As one of the mechanisms by which NK cells kill cancer cells is ADCC, combining adoptive NK cell therapy with therapeutic antibodies is of interest. Studying ADCC in spontaneous canine cancers may be feasible in some cases with murine, chimeric, or humanized antibodies, as canine Fc gamma receptors bind to dog, human, and mouse IgGs. However, caninized therapeutic antibodies may be preferred, as species differences in affinity may result in significant differences in activity, and eventual alloimmunization and neutralization by the host may significantly alter the antibody half-life of non-canine antibodies $(68,69)$. Of great interest is the genetic modification of NK cells to express chimeric antigen receptors (CAR) to target and enhance their killing $(70,71)$. Clinical trials investigating this approach are in their early stages in people. However, investigation of new CAR-NK constructs in dogs with osteosarcoma could address questions of toxicity, tumor targeting, immunologic response and antitumor activity. An important hurdle to genetic modification of NK cells has been their relative resistance to lentiviral and retroviral transduction $(24,72)$. Our group recently developed a method for genome editing of human primary and expanded NK cells using Cas9 ribonucleoprotein complexes (Cas9/RNPs) that allows for efficient knockout of genes in NK cells, thus opening the door for novel and innovative genetic modification strategies, including modifications that would affect tumor targeting and NK cell activation state, in vivo proliferative 
capacity, and cytotoxicity $(73,74)$. As the use of genetically modified cells in humans has even more significant regulatory hurdles to overcome compared to similar trials in dogs, clinical trials in dogs can speed the evaluation of novel approaches, identify those that are more promising, and provide additional useful safety data to inform subsequent human trials. As noted above, because of the ability to easily acquire patient biospecimens, including tumor biopsies, and the relatively comparable size to humans, the model is ideal for investigating effects on tumor targeting achieved with different CAR-NK constructs and for studying novel NK cell labeling and imaging techniques (65-67).

\section{REFERENCES}

1. Anfinsen KP, Grotmol T, Bruland OS, Jonasdottir TJ. Breed-specific incidence rates of canine primary bone tumors-a population based survey of dogs in Norway. Can J Vet Res. (2011) 75:209-15.

2. Fenger JM, London CA, Kisseberth WC. Canine osteosarcoma: a naturally occurring disease to inform pediatric oncology. ILAR J. (2014) 55:69-85. doi: 10.1093/ilar/ilu009

3. LaRue SM, Withrow SJ, Powers BE, Wrigley RH, Gillette EL, Schwarz PD, et al. Limb-sparing treatment for osteosarcoma in dogs. J Am Vet Med Assoc. (1989) 195:1734-44.

4. Stevenson S, Shaffer JW, Goldberg VM. The humoral response to vascular and nonvascular allografts of bone. Clin Orthop Relat Res. (1996) 326:86-95. doi: 10.1097/00003086-199605000-00011

5. Straw RC, Powers BE, Withrow SJ, Cooper MF, Turner AS. The effect of intramedullary polymethylmethacrylate on healing of intercalary cortical allografts in a canine model. J Orthop Res. (1992) 10:434-9. doi: 10.1002/jor.1100100316

6. Rodriguez CO, Jr., Crabbs TA, Wilson DW, Cannan VA, Skorupski KA, et al. Aerosol gemcitabine: preclinical safety and in vivo antitumor activity in osteosarcoma-bearing dogs. J Aerosol Med Pulm Drug Deliv. (2010) 23:197-206. doi: 10.1089/jamp.2009.0773

7. Withrow SJ, Thrall DE, Straw RC, Powers BE, Wrigley RH, Larue SM, et al. Intra-arterial cisplatin with or without radiation in limb-sparing for canine osteosarcoma. Cancer. (1993) 71:2484-90. doi: 10.1002/10970142(19930415)71:8<2484::AID-CNCR2820710810>3.0.CO;2-D

8. Paoloni MC, Mazcko C, Fox E, Fan T, Lana S, Kisseberth W, et al. Rapamycin pharmacokinetic and pharmacodynamic relationships in osteosarcoma: a comparative oncology study in dogs. PLoS One. (2010) 5:e11013. doi: 10.1371/journal.pone.0011013

9. Kurzman ID, MacEwen EG, Rosenthal RC, Fox LE, Keller ET, Helfand SC, et al. Adjuvant therapy for osteosarcoma in dogs: results of randomized clinical trials using combined liposome-encapsulated muramyl tripeptide and cisplatin. Clin Cancer Res. (1995) 1:1595-601.

10. MacEwen EG, Kurzman ID, Rosenthal RC, Smith BW, Manley PA, Roush $\mathrm{JK}$, et al. Therapy for osteosarcoma in dogs with intravenous injection of liposome-encapsulated muramyl tripeptide. J Natl Cancer Inst. (1989) 81:9358. doi: 10.1093/jnci/81.12.935

11. Mason NJ, Gnanandarajah JS, Engiles JB, Gray F, Laughlin D, GaurnierHausser A, et al. Immunotherapy with a HER2-targeting listeria induces HER2-specific immunity and demonstrates potential therapeutic effects in a phase I trial in canine osteosarcoma. Clin Cancer Res. (2016) 22:438090. doi: 10.1158/1078-0432.CCR-16-0088

12. Finck A, Gill SI, June CH. Cancer immunotherapy comes of age and looks for maturity. Nat Commun. (2020) 11:3325. doi: 10.1038/s41467-020-17140-5

13. Singh AK, McGuirk JP. CAR $T$ cells: continuation in a revolution of immunotherapy. Lancet Oncol. (2020) 21:e168e78. doi: 10.1016/S1470-2045(19)30823-X

14. Mason NJ. Comparative immunology and immunotherapy of canine osteosarcoma. Adv Exp Med Biol. (2020) 1258:199221. doi: 10.1007/978-3-030-43085-6_14

\section{DATA AVAILABILITY STATEMENT}

The original contributions presented in the study are included in the article/supplementary material, further inquiries can be directed to the corresponding author/s.

\section{AUTHOR CONTRIBUTIONS}

WK and DL contributed equally to the conception of this perspective and wrote sections of the manuscript. WK wrote the first draft of the manuscript. Both authors contributed to manuscript revision, read, and approved the submitted version.

15. Lee DA. Cellular therapy: Adoptive immunotherapy with expanded natural killer cells. Immunol Rev. (2019) 290:85-99. doi: 10.1111/imr.12793

16. Choucair K, Duff JR, Cassidy CS, Albrethsen MT, Kelso JD, Lenhard A, et al. Natural killer cells: a review of biology, therapeutic potential and challenges in treatment of solid tumors. Future Oncol. (2019) 15:305369. doi: 10.2217/fon-2019-0116

17. Kim R. Effects of surgery and anesthetic choice on immunosuppression and cancer recurrence. J Transl Med. (2018) 16:8. doi: 10.1186/s12967-018-1389-7

18. Miyata T, Kodama T, Honma R, Nezu Y, Harada Y, Yogo T, et al. Influence of general anesthesia with isoflurane following propofol-induction on natural killer cell cytotoxic activities of peripheral blood lymphocytes in dogs. J Vet Med Sci. (2013) 75:917-21. doi: 10.1292/jvms.12-0436

19. Rosental B, Appel MY, Yossef R, Hadad U, Brusilovsky M, Porgador A. The effect of chemotherapy/radiotherapy on cancerous pattern recognition by NK cells. Curr Med Chem. (2012) 19:1780-91. doi: 10.2174/092986712800099730

20. Chen J, Liu X, Zeng Z, Li J, Luo Y, Sun W, et al. Immunomodulation of NK cells by ionizing radiation. Front Oncol. (2020) 10:874. doi: 10.3389/fonc.2020.00874

21. Zingoni A, Fionda C, Borrelli C, Cippitelli M, Santoni A, Soriani A. Natural killer cell response to chemotherapy-stressed cancer cells: role in tumor immunosurveillance. Front Immunol. (2017) 8:1194. doi: 10.3389/fimmu.2017.01194

22. Bonifant CL, Jackson HJ, Brentjens RJ, Curran KJ. Toxicity and management in CAR T-cell therapy. Mol Ther Oncolytics. (2016) 3:16011. doi: $10.1038 /$ mto.2016.11

23. Sterner RC, Sterner RM. CAR-T cell therapy: current limitations and potential strategies. Blood Cancer J. (2021) 11:69. doi: 10.1038/s41408-021-00459-7

24. Mehta RS, Rezvani K. Chimeric antigen receptor expressing natural killer cells for the immunotherapy of cancer. Front Immunol. (2018) 9:283. doi: 10.3389/fimmu.2018.00283

25. Foltz JA, Somanchi SS, Yang Y, Aquino-Lopez A, Bishop EE, Lee DA. NCR1 expression identifies canine natural killer cell subsets with phenotypic similarity to human natural killer cells. Front Immunol. (2016) 7:521. doi: 10.3389/fimmu.2016.00521

26. Graves SS, Gyurkocza B, Stone DM, Parker MH, Abrams K, Jochum C, et al. Development and characterization of a canine-specific anti-CD94 (KLRD-1) monoclonal antibody. Vet Immunol Immunopathol. (2019) 211:108. doi: 10.1016/j.vetimm.2019.03.005

27. Grondahl-Rosado C, Bonsdorff TB, Brun-Hansen HC, Storset AK. NCR1+ cells in dogs show phenotypic characteristics of natural killer cells. Vet Res Commun. (2015) 39:19-30. doi: 10.1007/s11259-014-9624-Z

28. Huang YC, Hung SW, Jan TR, Liao KW, Cheng CH, Wang YS, et al. CD5low expression lymphocytes in canine peripheral blood show characteristics of natural killer cells. J Leukoc Biol. (2008) 84:1501-10. doi: 10.1189/jlb. 0408255

29. Pittari G, Fregni G, Roguet L, Garcia A, Vataire AL, Wittnebel S, et al. Early evaluation of natural killer activity in post-transplant acute myeloid leukemia patients. Bone Marrow Transplant. (2010) 45:86271. doi: $10.1038 /$ bmt.2009.265

30. Cheent K, Khakoo SI. Natural killer cells: integrating diversity with function. Immunology. (2009) 126:449-57. doi: 10.1111/j.1365-2567.2009.03045.x 
31. Grondahl-Rosado C, Boysen P, Johansen GM, Brun-Hansen H, Storset AK. NCR1 is an activating receptor expressed on a subset of canine NK cells. Vet Immunol Immunopathol. (2016) 177:7-15. doi: 10.1016/j.vetimm.2016.05.001

32. Gingrich AA, Modiano JF, Canter RJ. Characterization and potential applications of dog natural killer cells in cancer immunotherapy. J Clin Med. (2019) 8:1802. doi: 10.3390/jcm8111802

33. Tullius BP, Setty BA, Lee DA. Natural killer cell immunotherapy for osteosarcoma. Adv Exp Med Biol. (2020) 1257:14154. doi: 10.1007/978-3-030-43032-0_12

34. Ljunggren HG, Karre K. In search of the 'missing self': MHC molecules and NK cell recognition. Immunol Today. (1990) 11:237-44. doi: 10.1016/0167-5699(90)90097-S

35. Freud AG, Mundy-Bosse BL, Yu J, Caligiuri MA. The broad spectrum of human natural killer cell diversity. Immunity. (2017) 47:820-33. doi: 10.1016/j.immuni.2017.10.008

36. McDonough SP, Moore PF. Clinical, hematologic, and immunophenotypic characterization of canine large granular lymphocytosis. Vet Pathol. (2000) 37:637-46. doi: 10.1354/vp.37-6-637

37. Lin CS, Chang CP, Chiang HC, Chuang TF, Hsu CH, Liu CC. Activating natural killer (NK) cytotoxicity of canine CD5(-)CD21(-) cells requires low surface CD5 density NK cells. Iran J Vet Res. (2018) 19:87-95.

38. Lin YC, Huang YC, Wang YS, Juang RH, Liao KW, Chu RM. Canine CD8 $\mathrm{T}$ cells showing NK cytotoxic activity express mRNAs for NK cellassociated surface molecules. Vet Immunol Immunopathol. (2010) 133:14453. doi: 10.1016/j.vetimm.2009.07.013

39. Shin DJ, Park JY, Jang YY, Lee JJ, Lee YK, Shin MG, et al. Ex vivo expansion of canine cytotoxic large granular lymphocytes exhibiting characteristics of natural killer cells. Vet Immunol Immunopathol. (2013) 153:24959. doi: 10.1016/j.vetimm.2013.03.006

40. Pessino A, Sivori S, Bottino C, Malaspina A, Morelli L, Moretta L, et al. Molecular cloning of NKp46: a novel member of the immunoglobulin superfamily involved in triggering of natural cytotoxicity. J Exp Med. (1998) 188:953-60. doi: 10.1084/jem.188.5.953

41. Gagnier L, Wilhelm BT, Mager DL. Ly49 genes in non-rodent mammals. Immunogenetics. (2003) 55:109-15. doi: 10.1007/s00251-003-0558-9

42. Fang F, Xiao W, Tian Z. Challenges of NK cell-based immunotherapy in the new era. Front Med. (2018) 12:440-50. doi: 10.1007/s11684-0180653-9

43. Smyth MJ, Hayakawa Y, Takeda K, Yagita H. New aspects of natural-killercell surveillance and therapy of cancer. Nat Rev Cancer. (2002) 2:85061. doi: $10.1038 / \operatorname{nrc} 928$

44. Buddingh EP, Schilham MW, Ruslan SE, Berghuis D, Szuhai K, Suurmond J, et al. Chemotherapy-resistant osteosarcoma is highly susceptible to IL-15activated allogeneic and autologous NK cells. Cancer Immunol Immunother. (2011) 60:575-86. doi: 10.1007/s00262-010-0965-3

45. Sordo-Bahamonde C, Lorenzo-Herrero S, Payer AR, Gonzalez S, Lopez-Soto A. Mechanisms of apoptosis resistance to NK cell-mediated cytotoxicity in cancer. Int J Mol Sci. (2020) 21:3726. doi: 10.3390/ijms21103726

46. Fernandez L, Valentin J, Zalacain M, Leung W, Patino-Garcia A, PerezMartinez A. Activated and expanded natural killer cells target osteosarcoma tumor initiating cells in an NKG2D-NKG2DL dependent manner. Cancer Lett. (2015) 368:54-63. doi: 10.1016/j.canlet.2015.07.042

47. Mirzaei HR, Rodriguez A, Shepphird J, Brown CE, Badie B. Chimeric antigen receptors $\mathrm{T}$ cell therapy in solid tumor: challenges and clinical applications. Front Immunol. (2017) 8:1850. doi: 10.3389/fimmu.2017.01850

48. Castriconi R, Cantoni C, Della Chiesa M, Vitale M, Marcenaro E, Conte $\mathrm{R}$, et al. Transforming growth factor beta 1 inhibits expression of NKp30 and NKG2D receptors: consequences for the NK-mediated killing of dendritic cells. Proc Natl Acad Sci U S A. (2003) 100:41205. doi: 10.1073/pnas.0730640100

49. Dasgupta S, Bhattacharya-Chatterjee M, O'Malley BW, Jr., Chatterjee SK. Inhibition of NK cell activity through TGF-beta 1 by down-regulation of NKG2D in a murine model of head and neck cancer. J Immunol. (2005) 175:5541-50. doi: 10.4049/jimmunol.175.8.5541

50. Trotta R, Dal Col J, Yu J, Ciarlariello D, Thomas B, Zhang X, et al. TGFbeta utilizes SMAD3 to inhibit CD16-mediated IFN-gamma production and antibody-dependent cellular cytotoxicity in human NK cells. J Immunol. (2008) 181:3784-92. doi: 10.4049/jimmunol.181.6.3784
51. Xu X, Zhang J, Zhan S, Li Z, Liu X, Zhang H, et al. TGF- $\beta 1$ improving abnormal pregnancy outcomes induced by Toxoplasma gondii infection: regulating NKG2D/DAP10 and killer subset of decidual NK cells. Cell Immunol. (2017) 317:9-17. doi: 10.1016/j.cellimm.2017.04.004

52. Barretina J, Caponigro G, Stransky N, Venkatesan K, Margolin AA, Kim S, et al. The Cancer Cell Line Encyclopedia enables predictive modelling of anticancer drug sensitivity. Nature. (2012) 483:603-7. doi: 10.1038/nature11003

53. Portela RF, Fadl-Alla BA, Pondenis HC, Byrum ML, Garrett LD, Wycislo KL, et al. Pro-tumorigenic effects of transforming growth factor beta 1 in canine osteosarcoma. J Vet Intern Med. (2014) 28:894-904. doi: 10.1111/jvim.12348

54. Foltz JA, Moseman JE, Thakkar A, Chakravarti N, Lee DA. TGF $\beta$ imprinting during activation promotes natural killer cell cytokine hypersecretion. Cancers (Basel). (2018) 10:423. doi: 10.3390/cancers 10110423

55. Denman CJ, Senyukov VV, Somanchi SS, Phatarpekar PV, Kopp LM, Johnson JL, et al. Membrane-bound IL-21 promotes sustained ex vivo proliferation of human natural killer cells. PLoS One. (2012) 7:e30264. doi: 10.1371/journal.pone.0030264

56. Canter RJ, Grossenbacher SK, Foltz JA, Sturgill IR, Park JS, Luna JI, et al. Radiotherapy enhances natural killer cell cytotoxicity and localization in preclinical canine sarcomas and first-in-dog clinical trial. J Immunother Cancer. (2017) 5:98. doi: 10.1186/s40425-017-0305-7

57. Ciurea SO, Schafer JR, Bassett R, Denman CJ, Cao K, Willis D, et al Phase 1 clinical trial using mbIL21 ex vivo-expanded donor-derived NK cells after haploidentical transplantation. Blood. (2017) 130:185768. doi: 10.1182/blood-2017-05-785659

58. Khatua S, Cooper LJN, Sandberg DI, Ketonen L, Johnson JM, Rytting $\mathrm{ME}$, et al. Phase I study of intraventricular infusions of autologous ex vivo expanded NK cells in children with recurrent medulloblastoma and ependymoma. Neuro Oncol. (2020) 22:1214-25. doi: 10.1093/neuonc/noaa047

59. Judge SJ, Yanagisawa M, Sturgill IR, Bateni SB, Gingrich AA, Foltz JA, et al. Blood and tissue biomarker analysis in dogs with osteosarcoma treated with palliative radiation and intra-tumoral autologous natural killer cell transfer. PLoS One. (2020) 15:e0224775. doi: 10.1371/journal.pone.0224775

60. Fehniger TA, Miller JS, Stuart RK, Cooley S, Salhotra A, Curtsinger J, et al. A phase 1 trial of CNDO-109-activated natural killer cells in patients with high-risk acute myeloid leukemia. Biol Blood Marrow Transplant. (2018) 24:1581-9. doi: 10.1016/j.bbmt.2018.03.019

61. Graves SS, Mathes DW, Georges GE, Kuhr CS, Chang J, Butts TM, et al. Long-term tolerance to kidney allografts after induced rejection of donor hematopoietic chimerism in a preclinical canine model. Transplantation. (2012) 94:562-8. doi: 10.1097/TP.0b013e3182646bf1

62. Hilgendorf I, Weirich V, Zeng L, Koppitz E, Wegener R, Freund, et al. Canine haematopoietic chimerism analyses by semiquantitative fluorescence detection of variable number of tandem repeat polymorphism. Vet Res Commun. (2005) 29:103-10. doi: 10.1023/B:VERC.0000047486.01458.c5

63. Rosinski SL, Graves SS, Higginbotham DA, Storb R. Mixed chimerism renders residual host dendritic cells incapable of alloimmunization of the marrow donor in the canine model of allogeneic marrow transplantation. Chimerism. (2015) 6:54-64. doi: 10.1080/19381956.2016.1270483

64. Thiede C. Diagnostic chimerism analysis after allogeneic stem cell transplantation: new methods and markers. Am J Pharmacogenomics. (2004) 4:177-87. doi: 10.2165/00129785-200404030-00005

65. Kennis BA, Michel KA, Brugmann WB, Laureano A, Tao RH, Somanchi SS, et al. Monitoring of intracerebellarly-administered natural killer cells with fluorine-19 MRI. J Neurooncol. (2019) 142:395-407. doi: 10.1007/s11060-019-03091-5

66. Somanchi SS, Kennis BA, Gopalakrishnan V, Lee DA, Bankson JA. In vivo (19)F-magnetic resonance imaging of adoptively transferred NK cells. Methods Mol Biol. (2016) 1441:317-32. doi: 10.1007/978-1-4939-36 84-7_27

67. Sato N, Stringaris K, Davidson-Moncada JK, Reger R, Adler SS, Dunbar $\mathrm{C}$, et al. In vivo tracking of adoptively transferred natural killer cells in rhesus macaques using (89)zirconium-oxine cell labeling and PET imaging. Clin Cancer Res. (2020) 26:2573-81. doi: 10.1158/1078-0432.CCR-1 9-2897

68. Bergeron LM, McCandless EE, Dunham S, Dunkle B, Zhu $\mathrm{Y}$, Shelly J, et al. Comparative functional characterization of 
canine IgG subclasses. Vet Immunol Immunopathol. (2014) 157:31-41. doi: 10.1016/j.vetimm.2013.10.018

69. Kim Y, Lee SH, Kim CJ, Lee JJ, Yu D, Ahn S, et al. Canine nonB, non-T NK lymphocytes have a potential antibody-dependent cellular cytotoxicity function against antibody-coated tumor cells. BMC Vet Res. (2019) 15:339. doi: 10.1186/s12917-019-2068-5

70. Hu Y, Tian ZG, Zhang C. Chimeric antigen receptor (CAR)-transduced natural killer cells in tumor immunotherapy. Acta Pharmacol Sin. (2018) 39:167-76. doi: 10.1038/aps.2017.125

71. Lin C, Zhang J. Reformation in chimeric antigen receptor based cancer immunotherapy: Redirecting natural killer cell. Biochim Biophys Acta Rev Cancer. (2018) 1869:200-15. doi: 10.1016/j.bbcan.201 8.01 .005

72. Rezvani K, Rouce R, Liu E, Shpall E. Engineering natural killer cells for cancer immunotherapy. Mol Ther. (2017) 25:176981. doi: 10.1016/j.ymthe.2017.06.012

73. Naeimi Kararoudi M, Dolatshad H, Trikha P, Hussain SA, Elmas E, Foltz JA, et al. Generation of knock-out primary and expanded human NK cells using Cas9 ribonucleoproteins. J Vis Exp. (2018) 136:58237. doi: 10.3791/ 58237
74. Naeimi Kararoudi M, Nagai Y, Elmas E, Pereira MSF, Ali SA, Imus PH, et al. CD38 deletion of human primary NK cells eliminates daratumumab-induced fratricide and boosts their effector activity. Blood. (2020) 136:241627. doi: 10.1182/blood.2020006200

Conflict of Interest: DL holds stocks and options in Courier Therapeutics, Caribou Biosciences, and Kiadis Pharma; received consulting fees from Kiadis Pharma; received research grants from Kiadis Pharma; and has intellectual property licensed to Kiadis Pharma from which royalties are received.

The remaining author declares that the research was conducted in the absence of any commercial or financial relationships that could be construed as a potential conflict of interest.

Copyright (c) 2021 Kisseberth and Lee. This is an open-access article distributed under the terms of the Creative Commons Attribution License (CC BY). The use, distribution or reproduction in other forums is permitted, provided the original author(s) and the copyright owner(s) are credited and that the original publication in this journal is cited, in accordance with accepted academic practice. No use, distribution or reproduction is permitted which does not comply with these terms. 